\title{
Erratum to: The relationship between repetition suppression and face perception
}

\author{
Petra Hermann $^{1,2}$ • Mareike Grotheer ${ }^{3,4}$ - Gyula Kovács ${ }^{3,4,5}$ • Zoltán Vidnyánszky ${ }^{1,5}$
}

Published online: 15 August 2016

(C) Springer Science+Business Media New York 2016

Erratum to: Brain Imaging and Behavior (2016)

DOI 10.1007/s11682-016-9575-9

The authors regret the inadvertent omission of the following funding information:

P.H. and Z.V. were supported by a grant from the Hungarian Brain Research Program (KTIA_13_NAP-A-I/18).

The online version of the original article can be found at doi:10.1007 /s11682-016-9575-9

Petra Hermann

hermann.petra@ttk.mta.hu

1 Brain Imaging Centre, Research Centre for Natural Sciences, Hungarian Academy of Sciences, Magyar tudósok körútja 2,

Budapest 1117, Hungary

2 Faculty of Information Technology and Bionics, Pázmány Péter Catholic University, Budapest, Hungary

3 Institute of Psychology, Friedrich-Schiller-University of Jena, Jena, Germany

4 DFG Research Unit Person Perception, Friedrich-Schiller-University of Jena, Jena, Germany

5 Department of Cognitive Science, Budapest University of Technology and Economics, Budapest, Hungary 